\title{
PENGARUH MEDIA PEMBELAJARAN CORONG HITUNG TERHADAP HASIL BELAJAR SISWA DALAM MATERI PERKALIAN
}

\author{
Endah Yuli Widi Astuti*
}

Pendidikan Guru sekolah Dasar Fakultas Ilmu Pendidikan Universitas PGRI Semarang

\begin{abstract}
Abstrak:Tujuan penelitian ini untuk mengetahui penggunaan Media Pembelajaran Corong Hitung berpengaruh terhadap hasil belajar siswa. Jenis penelitian ini adalah eksperimen, Populasi dalam penelitian ini adalah seluruh siswa kelas II SDN Jatiroto 01 Kayen. Sampel dalam penelitian ini adalah kelas II yang berjumlah 20 siswa dengan menggunakan sampel jenuh. Desain penelitian eksperimen menggunakan Pre Experimental Design yang digunakan adalah One Group Pretest-Posttest Design. Berdasarkan hasil analisis data normalitas tahap awal pretest diperoleh $\mathrm{L}_{0}=0,129<$ $\mathrm{L}_{\text {tabel }}=0,190$ maka $\mathrm{H}_{0}$ diterima dan data berasal dari distribusi normal. Begitupula dengan hasil analisis data normalitas tahap akhir posttest diperoleh $\mathrm{L}_{0}=0,140<\mathrm{L}_{\text {tabel }}=$ 0,190 maka $\mathrm{H}_{0}$ diterima dan data berasal dari distribusi normal. Selanjutnya perhitungan uji $\mathrm{t}$ terhadap hasil belajar diperoleh $\mathrm{t}_{\text {hitung }}=9,372>\mathrm{t}_{\text {tabel }}=1,729$. Maka $\mathrm{H}_{\mathrm{i}}$ diterima. Hal ini berarti hasil belajar Matematika Siswa kelas II SDN Jatiroto 01 Kayen mencapai KKM 65 dan hasil perhitungan ketuntasan belajar siswa di kelas mencapai $85 \%$. Media Pembelajaran Corong Hitung berpengaruh terhadap hasil belajar Matematika materi Perkalian siswa kelas II SDN Jatiroto 01.
\end{abstract}

Kata kunci : media pembelajaran corong hitung, hasil belajar matmatika

\begin{abstract}
The purpose of this study to determine the use of Learning Media Funnel Counts affect student learning outcomes. This research type is experiment, Population in this research is all student of class II SDN Jatiroto 01 Kayen. The sample in this study is class II which amounted to 20 students by using saturated samples. The experimental research design using Pre Experimental Design used is One Group Pretest-Posttest Design. Based on the result of pretest initialization normality data analysis obtained $\mathrm{L}_{0}=0,129<\mathrm{L}_{\text {table }}=0,190$ then $\mathrm{H}_{0}$ accepted and data come from normal distribution. Similarly with the results of data analysis posttest end-stage normality obtained $\mathrm{L}_{0}=0.140<\mathrm{L}$ table $=0.190$ then $\mathrm{H}_{0}$ is accepted and the data comes from the normal distribution. Furthermore, the calculation of $t$ test on the learning results obtained $\mathrm{t}$ arithmetic $=9,372>t$ table $=1.729$. Then $\mathrm{H}_{\mathrm{i}}$ accepted. This means that the result of learning of Mathematics of Grade II of SDN Jatiroto 01 Kayen reaches the minimum completeness criteria of 65 and the result of students' learning mastery in class reach 85\%. Learning Media Funnel Counting influences the learning outcomes Mathematics material Multiplication grade II students SDN Jatiroto 01
\end{abstract}

Key word: Learning Media Funnel Counts, matmatika's learned result

\footnotetext{
Alamat korespondensi: Jl. Sidodadi Timur No. 24 Semarang. Universitas PGRI Semarang

$76 \quad$ email: endahyuliwidi@gmail.com 


\section{PENDAHULUAN}

Matematika merupakan pembelajaran yang dianggap sulit bagi siswa. Hal itu disebabkan karena pandangan awal terhadap mata pelajaran ini yang sudah pesimis sehingga anak kesulitan dalam memahaminya. Selain itu matematika bersifat abstrak sehingga hal tersebut memaksa anak untuk aktif dalam menerka apa yang ada pada persoalan dalam pelajaran ini sehingga dalam pembelajarannya membutuhkan strategi dan media yang tepat. Media yang dibutuhkan siswa meruapakan media yang dapat membantu siswa dalam merangsang pikiran, perasaan kemampuan serta ketrampilannya sehingga dapat mendorong terjadinya proses belajar. Media pembelajaran adalah segala sesuatu yang dapat digunakaan unyuk menyalurkan pesan dan merangsang terjadinya proses belajar pada si pembelajar (Aqib, 2013: 8). Media pembelajaran secara umum adalah alat bantu yang dapat digunakan untuk menyampaikan pesan dalam kegiatan pembelajaran dan berfungsi untuk menarik minat siswa dalam mengikuti proses pembelajaran. Untuk itu media pembelajaran sangat penting bagi pendidik.

Pada kenyataannya, banyak guru sekolah dasar yang menyampaikan materi pembelajaran belum menggunakan metode yang bervariasi dan terbatasnya media yang menunjang proses belajar mengajar (Slameto,2013:43). Di Indonesia sendiri, pemanfaatan media dalam pembelajaran kurang sehingga siswa merasa bosan dan diam pada saat pembelajaran, diam disini bukan berarti paham terhadap materi melainkan mereka tidak dapat memahami materi yang telah disampaikan oleh guru. Perlu adanya media agar siswa lebih memahami materi yang diberikan (Susanto,2013:56). Selain itu, siswa sekolah dasar masih dalam tahap anakanak sehingga harus diberikan contoh yang kongkrit atau nyata dalam memahami suatu konsep (Arsyad, 2014:23).

Selama ini, pembelajaran matematika yang dilakukan di kelas II masih berpusat pada guru bukan berpusat pada siswa. Guru lebih mendominasi pembelajaran sedangkan siswa mendengarkan penjelasan dari guru dan mencatat materi yang diajarkan. Selan- 
jutnya guru memberikan soal latihan dan siswa diminta mengerjakan soal latihan tersebut. Dalam pembelajaran yang dilakukan, guru belum secara maksimal memberikan kesempatan kepada siswa untuk aktif dalam pembelajaran sehingga siswa pasif dan mengakibatkan rendahnya hasil belajar matematika.

Perkalian termasuk bagian yang penting dan merupakan salah satu materi yang sulit dipahami bagi sebagian besar siswa kelas II sekolah dasar. Hal tersebut sesuai dengan hasil ualangan pada materi perkalian ada siswa yang belum mencapai KKM (Kriteria Ketuntasan Manimal). KKM mata pelajaran Matematika di SD Negeri Jatiroto 01 yaitu 65. Siswa yang belum mencapai KKM berjumlah 16 dari 24 siswa kelas II SD Negeri Jatiroto 01. Hasil tersebut membuktikan bahwa nilai siswa pada mata pelajaran Matematika materi perkalian masih rendah. Dalam perkalian 4 x $5=20$, konsepnya siswa cenderung salah dan merasa kesulitan. Misalkan $3 \times 4=3+3+3+3=12$, dikatakan salah karena $3 \times 4=4+4+4$ = 12 (Sumarmi, 2009:121-122). Selama ini guru mengandalkan buku sebagai bahan mengajar, padahal disekitar siswa banyak benda yang dapat digunakan sebagai media untuk mengajarkan perkalian pada siswa.

Pembelajaran yang mendominasi guru sebagai pusat pembelajaran harus diubah, karena siswa bukan merupakan kain putih yang hanya dicoret-coret. Siswa harus aktif dan berfikir kongkrit dalam pembelajaraan matematika. Selain itu, pemilihan media juga harus diperhatikan. Pada kenyataannya, sebagian guru ketika mengajar belum menggunakan media pembelajaran secara maksimal. Guru menggunakan sumber belajar yang ada seperti buku paket dan LKS, sehingga siswa kurang tertarik dalam mengikuti pembelajaran dan mengakibatkan rendanya nilai siswa.

Berdasarkan permasalahan yang terjadi, peneliti mencoba menggunakan media yang dapat mempermudah serta menarik minat siswa dalam proses pembelajaran. Media yang dirasa dapat membantu yaitu Media Corong Hitung. Media corong hitung ini diharapkan mampu mempermudah siswa dalam melakukan perkalian, sehingga dapat mempengaruhi hasil belajar siswa. Media Corong Hitung merupakan media yang digunakan untuk mengajarkan 
perkalian. Media ini berbentuk balok dengan bagian atas berisi corong dan bagian bawah yang dilengkapi dengan laci.

\section{METODE}

Metode penelitian yang digunakan adalah metode penelitian eksperimen. Pada penelitian ini peneliti menggunakan rancangan penelitian pre exsperimental design dengan jenis one group pretest-posttest design. Pada desain ini subjek dikenakan perlakuan dengan dua kali pengukuran. Pengukuran pertama dengan pretest sebelum subjek diberi perlakuan media dan pengukuran yang kedua dilakukan setelah kegiatan dengan menggunakan media pembelajarn corong hitung (Soegeng, A.Y. 2015).

Bagan desain yang digunakan sebagai berikut :

$$
\mathrm{O}_{1} \longrightarrow \mathrm{X} \longrightarrow \mathrm{O}_{2}
$$

Pre-test $\longrightarrow$ perlakuan $\longrightarrow$ post-test Gambar 1 Desain Penelitian

Keterangan :

$0_{1}=$ Nilai Pre - test (sebelum diberi perlakuan)

$\mathrm{X}=$ Perlakuan

$\mathrm{O}_{2}=$ Nilai post - test (setelah diberi perlakuan)

(Arikunto, 2013: 124)
Prosedur rancangan sebagai berikut:

a) Lakukan tes awal $\mathrm{O}_{1}$, untuk mengukur skor rata-rata (mean) sebelum subjek mendapat perlakuan media pembelajaraan corong hitung.

b) Berikan perlakuan $X$, yaitu pembelajaran dengan menggunakan media pembelajaran corong hitung.

c) Lakukan tes akhir $\mathrm{O}_{2}$, untuk mengukur skor rata-rata setelah subjek mendapatkan perlakuan X.

\section{PEMBAHASAN}

Data hasil penelitian diperoleh dari nilai pretest dan posttest hasil belajar siswa. Nilai pretest dan posttest dinyatakan tuntas jika memenuhi KKM. Adapun Kriteria Ketuntasan Minimal (KKM) mata pelajaran Matematika SD Negeri Jatiroto 01 Kayen yaitu 65. Perhitungan nilai pretest dan nilai posttest setelah diberikan perlakuan hasilnya berbeda. Berikut tabel nilai pretest dan posttest siswa kelas II SD Negeri Jatiroto 01 Kayen.

Data hasil belajar nilai prestest dan postest siswa kelas II SD Negeri Jatiroto 01 Kayen tahun ajaran 2016/2017 dapat dilihat pada tabel berikut : 
Tabel. 1 Data Hasil Pretest dan Posttest

\begin{tabular}{lll}
\hline Keterangan & Pretest & Posttest \\
\hline Nilai tertinggi & 80 & 95 \\
Nilai terendah & 40 & 55 \\
Rata-rata & 60,75 & 78,25 \\
Siswa tuntas & 10 & 17 \\
\hline
\end{tabular}

Tabel 2. Hasil Uji Normalitas

\begin{tabular}{lllll}
\hline $\begin{array}{l}\text { Jenis } \\
\text { Test }\end{array}$ & $\mathrm{N}$ & $\mathrm{L}_{0}$ & $\mathrm{~L}_{\text {tabel }}$ & Kesimpulan \\
\hline Pretest & 20 & 0,129 & 0,190 & $\begin{array}{l}\text { Berdistibusi } \\
\text { Normal }\end{array}$ \\
Posttest & 20 & 0,140 & 0,190 & $\begin{array}{l}\text { Berdistribusi } \\
\text { normal }\end{array}$ \\
\hline
\end{tabular}

Berdasarkan Tabel 1 terdapat perbedaan antara nilai terendah, nilai tertinggi, nilai rata-rata kelas dan jumlah siswa yang tuntas pada saat pretest dan postest. Nilai pretest diperoleh nilai terendah 40 dan nilai tertinggi 80 sedangkan nilai postest diperoleh nilai terendah 55 dan nilai tertinggi 95. Nilai rata-rata pretest atau sebelum diberi perlakuan sebesar 60,75 , setelah diberikan perlakuan dengan menggunakan media pembelajaran corong hitung nilai rata-rata postest siswa yaitu 78,25 . Berdasarkan Data hasil penelitian menun- jukkan bahwa terdapat peningkatan antara pretest yang sebelum diberikan perlakuan dengan nilai posttest yang sudah diberikan perlakuan dengan menggunakan media pembelajaran corong hitung (Sugiyono. 2014).

Berdasarkan Tabel 2 perhitungan uji normalitas pretest diperoleh harga mutlak selisih yang paling besar $\mathrm{L}_{0}=$ 0,129 dengan $\mathrm{n}=20$ dan taraf nyata $\alpha=$ $5 \%$ dari daftar nilai kritis $\mathrm{L}$ didapat $\mathrm{L}_{\mathrm{ta}}$ bel $=0,190$ karena $\mathrm{L}_{0}<\mathrm{L}_{\text {tabel }}$ yaitu $0,129<$ 0,190 maka $\mathrm{H}_{0}$ diterima. Hasil uji normalitas menunjukkan bahwa data pretest siswa berasal dari populasi yang berdistribusi normal. Berdasarkan Tabel 2 perhitungan uji normalitas kelas responden hasil posttest diperoleh harga mutlak selisih yang paling besar $\mathrm{L}_{0}=$ 0,140 dengan $\mathrm{n}=20$ dan taraf nyata $\alpha=$ $5 \%$ dari daftar nilai kritis $\mathrm{L}$ didapat $\mathrm{L}_{\mathrm{ta}}$ bel $=0,190$ karena $\mathrm{L}_{0}<\mathrm{L}_{\text {tabel }}$ yaitu 0,140 $<0,190$ maka $\mathrm{H}_{0}$ diterima. Sehingga dapat disimpulkan bahwa data posttest siswa berasal dari populasi yang berdistribusi normal. 
Tabel 3 Hasil Perhitungan uji t

\begin{tabular}{|c|c|c|c|c|c|c|c|}
\hline Subjek & $\begin{array}{l}\text { Hasil } \\
\text { Belajar }\end{array}$ & $\begin{array}{l}\text { Rata- } \\
\text { Rata }\end{array}$ & $\mathrm{N}$ & $\mathrm{Md}$ & $\sum x^{2} d$ & $t_{\text {hitung }}$ & $\mathrm{t}_{\text {tabel }}$ \\
\hline $\begin{array}{l}\text { Kelas II SD } \\
\text { Negeri }\end{array}$ & Pretest & 60,75 & & & & & \\
\hline $\begin{array}{ll}\text { Jatiroto } & 01 \\
\text { Kayen } & \end{array}$ & posttest & 78,25 & 20 & 17,5 & 1325 & 9,372 & 1,729 \\
\hline
\end{tabular}

Berdasarkan Tabel 3 diperoleh harga $t_{\text {hitung }}=9,327$. Selanjutnya harga $t_{\text {hitung }}$ tersebut dibandingkan dengan $t_{\text {tabel }}$ $=1,729$ dengan dengan $\mathrm{db}=20-1$ pada taraf signifikan $\alpha=5 \%$, sehingga diperoleh harga $t_{\text {hitung }}>t_{\text {tabel }}$ yaitu 9,327>1,729. Dengan demikian $\mathrm{H}_{0}$ ditolak dan $\mathrm{H}_{\mathrm{i}}$ diterima. Hal ini pengaruh media pembelajaran corong hitung terhadap hasil belajar siswa dalam materi perkalian kelas II SDN Jatiroto 01 Kayen. Secara statistika hipotesis penggunaan media pembelajaran corong hitung berpengaruh terhadap hasil belajar siswa dalam materi perkalian kelas II SDN Jatiroto 01 Kayen terbukti.

Berdasarkan hasil uji tes awal atau pretest menunjukkan bahwa sebagian siswa nilainya belum mencapai KKM yang ditentukan sekolah yaitu 65 . Pada kelas eksperimen dengan rata-rata nilai pretest 60,75 terdapat 10 dari 20 siswa atau $50 \%$ dinyatakan tuntas dan
10 dari 20 siswa atau $50 \%$ dinyatakan tidak tuntas.

Hasil uji tes akhir atau posttest menunjukkan bahwa nilai rata-rata setelah diberikan perlakuan menjadi lebih baik dengan rata-rata nilai 78,25 terdapat 17 dari 20 siswa atau $85 \%$ siswa dinyatakan tuntas dan 3 dari 20 siswa atau $15 \%$ dinyatakan tidak tuntas. Siswa yang dinyatakan tidak tuntas berarti memiliki nilai yang belum mencapai KKM yang ditentukan yaitu 65. Selain itu 3 siswa tersebut masih mengalami kesulitan dalam pemahaman materi sehingga dalam menjawab soal mereka membutuhkan waktu yang lama. Dengan rata-rata nilai posttest 78,25 menunjukkan bahwa Media pembelajaran corong hitung memberikan pengaruh yang baik terhadap terhadap hasil belajar Matematika pada siswa kelas II SD N Jatiroto 01 Kayen. Perbedaan rata-rata nilai kelas menun- 
jukkan adanya perbedaan antara Media pembelajaran corong hitung dengan terbatasnya media yang digunakan pada saat pembelajaran.

Berdasarkan pengujian uji $\mathrm{t}$ diperoleh $t_{\text {hitung }}>t_{\text {tabel }}$ atau 9,327>1,729 sehingga Ho ditolak dan Hi diterima (Sugiyono. 2015). Dapat disimpulkan bahwa Media pembelajaran Corong Hitung berpengaruh terhadap hasil belajar siswa dalam materi perkalian kelas II SD Negeri Jatiroto 01 Kayen tahun ajaran 2016/2017. Hasil penelitian ini sesuai dengan teori Piaget yang menyatakan bahwa individu pada usia 7 sampai 11 tahun berada pada tahap operasional konkret. Individu pada tahap ini memerlukan benda-benda konkrit untuk menunjang proses belajar (Heruman, 2014). Media pembelajaran Corong Hitung membantu siswa dalam memahami materi perkalian. Siswa secara konkrit memecahkan masalah yang berkaitan dengan perkalian melalui pembelajaran yang menyenangkan dan media yang mudah digunakan (Suprijono,2017:34).

Pembelajaran menggunakan media pembelajaran corong hitung juga dapat mengoptimalkan belajar sehingga hasil belajar siswa meningkat. Sesuai penelitian Harnanto (2016) yang menyatakan alat peraga dapat digunakan untuk menyampaikan suatu isi pelajaran, memperjelas dan menarik perhatian siswa sehingga dapat mendorong proses pembelajaran yang pada akhirnya dapat meningkatakan hasil belajar, dengan digunakannya alat peraga pesan yang disampaikan menjadi lebih jelas dan mudah diterima siswa (Sukmadinata,2016). Disampaikan pula oleh Rahadi (2003: 10) dalam Harnanto (2016) alat peraga adalah alat (benda) yang digunakan untuk memeragakan fakta, konsep, prinsip, atau prosedur tertentu agar tampak lebih nyata/kongkrit. Sedangkan menurut Hamdani (2005) dalam Wibowo (2013) mengemukakan Media pembelajaran adalah bahan atau teknik yang digunakan dalam kegiatan belajar dengan maksud agar proses interaksi komunikasi edukasi antara guru dan siswa dapat berlangsung secara tepat guna dan berdayaguna (Sundayana, 2016:117).

Berdasarkan uraian tersebut, disimpulkan bahwa media pembelajaran dapat meningkatkan hasil belajar siswa dalam memahami materi yang diberikan guru dan dapat membantu siswa 
memecahkan masalah yang berkaitan dengan perkalian.

\section{KESIMPULAN}

Berdasarkan hasil penelitian dan pembahasan dalam penelitian ini dapat disimpulkan bahwa Media pembelajaran Corong Hitung berpengaruh terhadap hasil belajar siswa dalam materi perkalian kelas II SD Negeri Jatiroto 01 Kayen tahun ajaran 2016/2017. Hal ini dibuktikan dengan analisis uji $t$ dimana $t_{\text {hitung }}>t_{\text {tabel }}$ atau 9,327>1,729 dengan rata-rata nilai pada kelas adalah 78,25 dan persentase ketuntasan belajar mencapai $85 \%$. Pembelajaran dengan menggunakan media yang menarik akan dapat meningkatkan hasil belajar siswa, oleh karena itu penggunaan media pembelajaran corong hitung dalam materi perkalian dapat dikembangkan oleh guru untuk diterapakan pada materi lain. Media pembelajaran corong hitung memberikan pengaruh yang positif pada siswa sehingga guru dapat menerapkannya sebagai salah satu alternatif media pembelajaran yang digunakan untuk penjumlahan, pengurangan dan pembagian. Guru hendaknya menggunakan media pembelajaran yang tepat agar tercipta suasana belajar yang aktif, menyenangkan dan efektif sehingga diharapkan hasil belajar siswa dapat meningkat.

\section{DAFTAR PUSTAKA}

Arikunto, Suharsimi. 2013. Prosedur Penelitian Suatu Pendekatan Praktik. Jakarta: Rineka Cipta. 2013. Dasar-Dasar Evaluasi Pendidikan. Jakarta: Bumi Aksara.

Arsyad, Azhar. 2014. Media Pembelajaran. Kota Depok: PT Rajagrafindo Persada.

Aqib, Zainal. 2013. Model- Model, Media, dan Strategi Pembelajaran Kontekstual (Inovatif). Bandung. YramaWidya

Harnanto, Sugeng. 2016. "Alat Peraga Kotak Belajar Ajaib (KOBELA) dalam Pembelajaran Matematika Materi Perkalian dan Pembagian Sekolah Dasar”. Jurnal Pendas 3.1: 33-42. 
Heruman. 2014. Model Pembelajaran Matematika di Sekolah Dasar. Bandung: PT Remaja Rosdakarya.

Joko, Endro Wibowo. 2013. "Media Pembelajaran Interaktif Matematika Untuk Siswa Sekolah Dasar”. http://ijns.org/journal/index.php/seruni/article/view/584. Diakses 26 Maret 2016.

Slameto. 2013. Belajar dan Faktor-Faktor Yang Mempengaruhi. Jakarta. Rineka Cipta.

Soegeng, A.Y. 2015. Dasar-dasar Penelitian. Semarang: IKIP PGRI Semarang Press.

Sugiyono. 2014. Metode Penelitian Pendidikan. Bandung: Alfabeta 2015. Statistika Untuk Penelitian. Bandung: Alfabeta.

Sukmadinata, Syaodih. 2016: Metode Penelitian Pendidikan. Bandung: PT Remaja Rosdakarya

Sundayana, Rostina. 2016: Media dan Alat Peraga dalam Pembelajaran Matematika. Bandung: Alfabeta.

Suprijono, Agus. 2015. Cooperatif Learning. Yaogyakarta: Pustaka Pelajar.

Susanto, Ahmad. 2013. Teori Belajar \& Pembelajaran di Sekolah Dasar. Jakarta. Prenadamedia. 
